\title{
Controlled release of ethanehydroxy diphosphonate from polyurethane reservoirs to inhibit calcification of bovine pericardium used in bioprosthetic heart valves
}

\author{
Thomas P. Johnston*, James A. Boyd, Barbara L. Ciesliga, Frederick J. Schoen**, \\ Gordon Amidon *** and Robert J. Levy \\ Department of Pediatrics and Communicable Disease, The University of Michigan, Ann Arbor, MI 48109 (U.S.A.)
}

(Received 7 February 1989)

(Modified version received 1 June 1989)

(Accepted 22 September 1989)

Key words: Ethanehydroxy diphosphonate; Calcification; Bioprosthetic heart valve; Controlled release

\begin{abstract}
Summary
Calcification (CALC) of bioprosthetic heart valves (BHVs) fabricated from either glutaraldehyde-pretreated bovine pericardial tissue or porcine aortic valves is the most frequent cause of clinical failure of these devices. Previous studies have demonstrated that calcification is inhibited by diphosphonate compounds released into the vicinity of bioprosthetic tissue implanted subcutaneously in rats. Controlled release of the anticalcification agent ethanehydroxy diphosphonate (EHDP), as a 1:1 mixture of $\mathrm{Na}{ }_{2} \mathrm{EHDP}$ and CaEHDP from cylindrical polyurethane (PU) reservoirs $($ o.d. $=0.36 \mathrm{~cm}$, i.d. $=0.33 \mathrm{~cm}$, length $=4 \mathrm{~cm}$ ) fabricated by solvent casting was assessed in vitro and in vivo. The diffusivity $(D)$, determined independently using standard diffusion cells, for ionic EHDP diffusion across the PU membrane was $1.2 \times 10^{-10} \mathrm{~cm}^{2} / \mathrm{s}$. Volume influx of buffer into the reservoirs in vitro was observed experimentally to reach a maximum at 7.8 days $(288 \pm 44 \mu \mathrm{l})$ with a biexponential decline to $147 \pm 6 \mu 1$ at 70 days. The cumulative EHDP released in vitro after 70 days was $4.2 \pm 0.6 \%(4.8 \pm 0.7 \mathrm{mg}$ ) compared to $15.7 \pm 3.2 \%$ (18.1 $\pm 3.7 \mathrm{mg}$ ) in vivo (subcutaneously in 3 week-old, male, CD rats) over 21 days. The release rate of EHDP from the reservoirs was not a zero-order process. Reservoir administration of EHDP effectively inhibited pericardial BHV-CALC in 21 -day subdermal explants $\left(\mathrm{Ca}^{2+}=4.5 \pm 1.4 \mu \mathrm{g} \mathrm{Ca}{ }^{2+} / \mathrm{mg}^{2}\right.$ tissue; control, $\mathrm{Ca}^{2+}=120 \pm 13 \mu \mathrm{g} \mathrm{Ca}^{2+} / \mathrm{mg}$ tissue) without diphosphonate-related untoward effects at a dose of approx. $3 \mathrm{mg} / \mathrm{kg}$ per day.
\end{abstract}

* Present address: Department of Pharmaceutics (M/C 880) University of Illinois at Chicago, Chicago, IL 60612, U.S.A.

** Present address: Department of Pathology, Brigham and Women's Hospital and Harvard Medical School, Boston, MA 02115, U.S.A.

*** Present address: Department of Pharmaceutics, The University of Michigan, Ann Arbor, MI 48109, U.S.A.

Correspondence: R.J. Levy, Division of Pediatric Cardiology, C.S. Mott Children's Hospital, The University of Michigan Medical Center, Kresge II Research Laboratories, Room 5014, Ann Arbor, MI 48109-0576, IJ.S.A.

\section{Introduction}

Pathologic calcification is the primary process leading to sterile degeneration of bioprosthetic heart valves (Milano et al., 1984; Schoen and Levy, 1984; Schoen and Hobson, 1985; Schoen, 1987) fabricated from either glutaraldehyde-pretreated porcine aortic valves or bovine pericardium. Dysfunction of the calcified bioprosthetic heart valve typically results from either stenosis or secondary calcific tearing of the leaf- 
lets. Pathologic deposition of calcium phosphate crystals is also important in other cardiovascular diseases such as arteriosclerosis (Levy et al., 1983a), myocardial infarction (Hagler et al., 1981), valvular heart disease (Levy et al., 1980), and mineralization of the elastomeric blood-contacting surfaces of artificial heart devices (Pierce et al., 1980). Despite the prevalence of cardiovascular calcification, the pathophysiology of BHV calcification is incompletely understood (Schoen et al., 1985a, 1988). Recently, much research has been directed at developing satisfactory means for its prevention.

The calcification of bioprosthetic heart valves has been extensively investigated experimentally. Animal models utilized in studying BHV-CALC have involved orthotopic valve replacements or conduit-mounted valves in sheep and calves (Barnhart et al., 1982a; Levy et al., 1983b; Thubrikar et al., 1983: Gallo et al., 1987), and subcutaneous implants in mice (Levy et al., 1983c). rats (Levy et al., 1983d,e), and rabbits (Fishbein et al., 1982). Many of the pathologic findings from long-term clinical implants are simulated by the subcutaneous and circulatory animal models (Fishbein et al., 1982; Levy et al., 1983c,d; Barnhart et al., 1982b; Arbustini et al., 1984; Schoen et al., 1985b).

Ethanehydroxy diphosphonate (EHDP) has been shown to inhibit effectively experimental BHV calcification (Levy et al., 1985b,c). However, subcutaneous administration of EHDP to rats at doses greater than $15 \mathrm{mg} / \mathrm{kg}$ per day has been shown to be associated with adverse effects on overall somatic growth, bone development. and serum $\mathrm{Ca}^{2+}$ levels (Levy et al., 1987). Nevertheless, controlled release of EHDP from a variety of polymeric matrices directly into BHV tissue prevented BIIV-CALC using minimal local doses and avoided adverse effects (Levy et al.. 1985b,c; Golomb et al., 1986a,b. 1987).

The purpose of the present study was to fabricate controlled release polyurethane reservoirs and evaluate their in vitro release profiles and in vivo efficacy and function using the rat subdermal model of bioprosthetic tissue calcification. Additional experiments assessed the fluid dynamics during in vitro release and the diffusion coeffi- cient for EHDP through the polyurethane membrane used in our reservoirs. The advantage of the present drug delivery device compared to EHDPpolymer matrices is the potential for constant (zero-order) delivery of EHDP and replenishment of EHDP following drug exhaustion.

\section{Experimental}

\section{Materials}

Mitrathane (MPU-5), a medical grade polyether-urea-urethane, was provided by Matrix Medica (Wheatridge, $\mathrm{CO}$ ) as a $25 \% \mathrm{w} / \mathrm{v}$ solution in dimethylacetamide and as solvent-cast sheeting having a thickness of $150 \pm 6 \mu \mathrm{m}$. Disodium ethanehydroxy diphosphonate ( $\mathrm{Na}_{2}$ EHDP) was provided by Norwich Faton (Norwich NY). $\mathrm{Na}_{2}\left[{ }^{14} \mathrm{C}\right]$ EHDP (specific activity: $48.9 \mu \mathrm{Ci} / \mathrm{mmol}$ ) and the calcium salt of EHDP were provided by Proctor and Gamble (Cincinnati, $\mathrm{OH}$ ). $\mathrm{Na}_{2}\left[{ }^{14} \mathrm{C}\right]$ EHDP was diluted with unlabelled $\mathrm{Na}_{2}$ EHDP to yield a specific activity of $3800 \mathrm{dpm} / \mu \mathrm{mol}$. The diluted $\mathrm{Na}_{2}\left[{ }^{14} \mathrm{C}\right]$ EHDP was then mixed in a $1: 1$ ratio with CaEHDP and the resulting mixture sieved to obtain a uniform particle size of 90-106 $\mu \mathrm{m}$. Atomlight scintillation solution was obtained from New England Nuclear (Billerica, MA).

Parietal pericardium was obtained fresh at slaughter from steers and immediately placed in iced sterile saline for not longer than $1 \mathrm{~h}$. Superficial fat was dissected from the external surfaces and the pericardium then transferred to $0.8 \%$ glutaraldehyde (E.M. grade, Polyscience. Warrington, PA) in a physiologic buffer $(0.05 \mathrm{M}$ Hepes in $0.1 \mathrm{M} \mathrm{NaCl}, \mathrm{pH}$ 7.4) for a 2-week period to initiate cross-linking. The glutaraldehyde buffer containing the pericardium was stored at $4{ }^{\circ} \mathrm{C}$.

\section{Methods}

\section{Polyurethane membranes and reservoirs}

The medical grade polyurethane sheeting was used as received in the diffusion study after cutting $1 \times 1$ inch membranes to mount in each diffusion cell. Polyurethane reservoirs were fabricated by dipping teflon-coated steel rods $($ o.d. $=0.33$ $\mathrm{cm}$ ) into the polyurethane solution. Excess liquid 
polyurethane was removed and the rods suspended vertically to allow the organic solvent to volatilize. After air drying for 2 days, the reservoirs were removed from the teflon rods, one end of the reservoir was sealed with cyanoacrylate ester (Super Glue, Locktite, Cleveland, $\mathrm{OH}$ ), the reservoir filled with the presieved, powdered $\mathrm{Na}{ }_{2}\left[{ }^{14} \mathrm{C}\right] \mathrm{EHDP} / \mathrm{CaEHDP}$ mixture, and the second end sealed. Reservoirs fabricated by this procedure had a length of $4 \mathrm{~cm}$ and a wall thickness of $150 \pm 17 \mu \mathrm{m}$ (i.d. $=0.36 \mathrm{~cm}$, i.d. $=0.33 \mathrm{~cm}$ ). The resulting PU reservoirs contained an average of $229 \pm 3 \mathrm{mg}$ of the $1: 1 \quad \mathrm{Na}_{2}\left[{ }^{14} \mathrm{C}\right] \mathrm{EHDP} /$ CaEHDP mixture.

\section{In vitro release of $\mathrm{Na}_{2} l^{14} \mathrm{CJEHDP}$}

Preloaded reservoirs containing $\mathrm{Na}_{2}\left[{ }^{14} \mathrm{C}\right]-$ EHDP/CaEHDP (1:1) were incubated at $37^{\circ} \mathrm{C}$ in $24 \mathrm{ml}$ of a physiologic buffer $(0.05 \mathrm{M}$ Hepes adjusted to $0.15 \mathrm{M}$ with $\mathrm{NaCl}, \mathrm{pH} 7.4$ ) with constant stirring $(150 \mathrm{rpm})$ by using an orbital shaker (Lab Line, Melrose Park, CA). At specified time points over the 70 day in vitro release period, reservoirs were removed from the buffer, gently washed with distilled water to remove any radioactive drug solution adhering to the surface of the reservoir, and then placed in $24 \mathrm{ml}$ of fresh buffer. A $5 \mathrm{ml}$ aliquot of the receptor phase containing solubilized $\mathrm{Na}_{2}\left[{ }^{14} \mathrm{C}\right]$ FHDP was removed, combined with $15 \mathrm{ml}$ of the scintillation fluor and then counted for ${ }^{14} \mathrm{C}$ activity on a Beckman liquid scintillation counter (model no. 3801, Berkeley, CA). The release profiles of $\mathrm{Na}_{2}\left[{ }^{14} \mathrm{C}\right] \mathrm{EHDP}$ from the controlled release $\mathrm{PU}$ reservoirs were expressed as the cumulative $\% \mathrm{Na}_{2}\left[{ }^{14} \mathrm{C}\right]$ EHDP released vs time.

\section{Diffusion studies}

The value of $D$ for $\left[{ }^{14} \mathrm{C}\right] \mathrm{EHDP}$ diffusion across a $150 \mu \mathrm{m}$ thick PU film was determined using standard diffusion cells at $37^{\circ} \mathrm{C}$ with constant stirring. The receptor solution was a physiologic buffer (see above) preserved with $0.5 \%$ sodium azide. Periodically, samples of the receptor phase were removed, counted for ${ }^{14} \mathrm{C}$ activity in a liquid scintillation counter and the \% EHDP diffused calculated as a function of time.

\section{Reservoir volume influx studies}

Identical drug-loaded reservoirs (see above) were also assessed in vitro for volume influx of buffer during the 70 day release period. Reservoirs were removed from the buffer at regular intervals and the exterior surface blotted dry of surface adhering buffer. The reservoirs were then weighed on an analytical balance and the resulting weights compared to the initial preincubation wcight of the drug-loaded reservoir to calculate the amount (volume) of buffer imbibed.

\section{Rat subdermal studies}

Prior to implantation, 10 reservoirs were allowed to release EHDP into a physiologic buffer (see above) for 6 days (approx. $2 \times t_{\text {lag }}$ ) to ensure that release of EHDP from the reservoirs was proceeding at a constant rate (zero-order) based on preliminary results of the EHDP diffusion studies. Ten rats (3-week-old, male CD strain, Charles River Labs, Wilmington, MA) were implanted subcutaneously with drug-loaded reservoirs on the dorsal side adjacent to a $3.0 \times 0.9$ $\mathrm{cm}^{2}$ strip of glutaraldehyde-pretreated, bovine pericardial tissue. An additional 7 rats were implanted as above with BHV tissue adjacent to empty PU reservoirs. Reservoirs and BHV tissue were explanted at 21 days. A representative section of the BHV tissue was immediately fixed in a cacodylate-buffered $2.5 \%$ glutaraldehyde- $2 \%$ paraformaldehyde solution buffered at pII 7.2 (Karnovsky, 1965) for $24 \mathrm{~h}$ and then dehydrated in graded ethanol solutions (Levy et al., 1985b) prior to embedding in glycolmethylmethacrylate (JB-4, Polysciences, Warrington, PA). Sections $(2-3 \mu \mathrm{m})$ were stained with hematoxylin and eosin for overall morphologic analyses and Von Kossa's reagent for calcium phosphate (Levy et al., 1985b). The remaining portion of each piece of $\mathrm{BHV}$ tissue was prepared for quantitative analysis of calcium using atomic absorption spectroscopy (Levy et al., 1980, 1983d).

Explanted reservoirs were dried at $100^{\circ} \mathrm{C}$ for $12 \mathrm{~h}$, opened, and the luminal contents removed as a dry pellet. Each cylindrical, rod-shaped pellet was dissolved in $20 \mathrm{ml}$ of deionized water, the solution sonicated (Branson sonifier, model 250, 
Shelton, $\mathrm{CN}$ ) and then sampled $(5 \mathrm{ml})$ to determine ${ }^{14} \mathrm{C}$ activity.

\section{Data analysis}

All data were expressed as the mean \pm standard error of the mean (SE). The in vitro release and the diffusion studies expressed the mean cumulative percentage of $\left[{ }^{14}\right.$ C]EHDP released or diffused, respectively. Comparisons of means were performed using the Student's $t$-test. Polyexponential equations used to predict the time course for buffer influx into the reservoirs, amount of drug released from the reservoirs, and decrease in the value of the permeability $(D K)$ of MPU-5 to $\left[{ }^{14} \mathrm{C}\right]$ EHDP were determined according to a nonlinear least-squares regression routine (Bolt et al., 1984). Initial parameter estimates for the nonlinear fitting routine were obtained graphically via the method-of-residuals.

\section{Results and Discussion}

The present study has successfully demonstrated the fabrication and characterization of EHDP controlled release reservoirs. EHDP delivery was characterized in vitro and in vivo and the efficacy of this novel reservoir system was demonstrated in a rat subdermal calcification model.

\section{EHDP diffusion through Mitrathane}

The value of $D$ was calculated with Eqn. 1:

$D=l^{2} / 6 \cdot t_{\mathrm{lag}}$

where $t_{\text {lag }}$ denotes the lag-time (s) and $l$ is the polymer membrane thickness $(\mathrm{cm})$. Eqn. 1 assumes that a steady state has been achieved for a constant-activity reservoir device (Fig. 1) (Baker, 1987). The lag-time (3.58 days) for EHDP diffusion through the MPU-5 membrane $(0.015 \mathrm{~cm})$ was experimentally determined by back extrapolation to the $x$-axis of the steady-state portion of the curve illustrated in Fig. 1. Thus, the value of the apparent $D$ was determined to be $1.2 \times 10^{-10}$ $\mathrm{cm}^{2} / \mathrm{s}$.

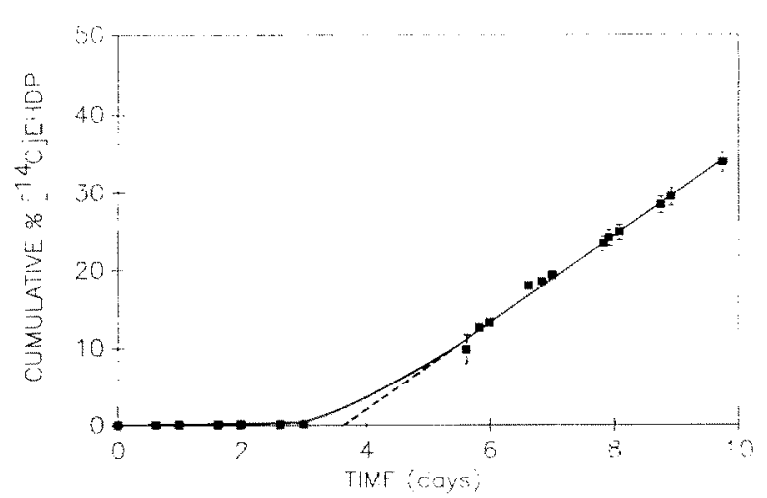

Fig. 1. Diffusion of $\mathrm{Na}_{2}$ EHDP through solvent-cast Mitrathane (MPU-5) membrane. (E) Mean \pm S.F.

Characterization of convective bulk flow

Rapid influx of physiologic buffer into the reservoir lumen was observed as early as $23 \mathrm{~h}$ after the initiation of in vitro release of $\left[{ }^{14} \mathrm{C}\right] \mathrm{EHDP}$ (Fig. 2). Following $23 \mathrm{~h}$ of in vitro release, approx. $170 \pm 10 \mu \mathrm{l}$ of physiologic buffer (approx. $1 / 2$ the reservoir's calculated internal volume) had been imbibed. Continual uptake of fluid to 7.8 days was observed experimentally, whereupon the volume of fluid inside the reservoir began to decrease in a biexponential fashion for the duration of the in vitro release period. The internal volume of the reservoir as a function of time was estimated as the sum of the internal volume of the empty reservoir and the volume of buffer imbibed in excess (net buffer imbibed, Fig. 2) of the volume required for dissolution of the $\mathrm{Na}_{2} \mathrm{EHDP}$ and

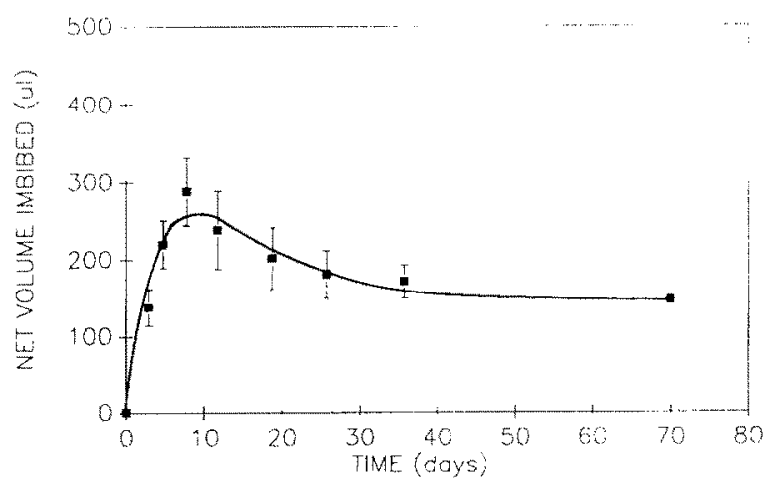

Fig. 2. Reservoir volume influx vs in vitro incubation time in physiologic buffer. ( $\mathbf{\square})$ Mean $\pm \mathrm{SE}$; (—_ nonlinear regression (Rolt et al., 1984) fit of the data. 
TABLE 1

Controlled release reservoir transport parameters: macroconstants associated with polyexponential equations

\begin{tabular}{|c|c|c|c|c|c|c|}
\hline \multirow[t]{2}{*}{ Parameter $(t)$} & \multicolumn{3}{|c|}{ Pre-exponential coefficient } & \multicolumn{3}{|c|}{ Characteristic time $\left(\right.$ day $\left.^{-1}\right)$} \\
\hline & $\bar{A}$ & $B$ & $C$ & $\overline{\lambda_{1}}$ & $\lambda_{2}$ & $i_{3}$ \\
\hline $\begin{array}{l}\text { Volume imbibed, } \\
V(t)^{a}\end{array}$ & 3546 & 149 & -3703 & 0.136 & $2.54 \times 10^{-5}$ & 0.153 \\
\hline $\begin{array}{l}\text { Permeability, } \\
\qquad P(t)\end{array}$ & $4.93 \times 10^{-11}$ & $4.18 \times 10^{-11}$ & - & 0.479 & 0.0462 & - \\
\hline $\begin{array}{l}\text { Diffusion } \\
\text { coefficient, } D(t)\end{array}$ & $9.30 \times 10^{-11}$ & $7.88 \times 10^{-11}$ & - & 0.479 & 0.0462 & - \\
\hline
\end{tabular}

which was required to fill the void volume (30-40\%) between the CaEHDP salt particles following $\mathrm{Na}_{2} \mathrm{EHDP}$ dissolution. The volume of the buffer imbibed in excess of the volume needed to facilitate dissolution of $\mathrm{Na}_{2} \mathrm{EHDP}$ and to fill the void volume between the poorly soluble CaEHDP particles following $\mathrm{Na}_{2}$ EHDP dissolution was calculated by using a triexponential equation ( $\mathrm{Ta}-$ ble 1) and is shown in Fig. 2. If it is assumed that bulk flow of buffer into the cylindrical reservoir caused the reservoir to expand in a uniform, cylindrical manner, then it should be possible to quantitate the surface area $(A)$ of the reservoir as a function of time knowing only the time-dependent internal volume of the reservoir. Theoretically, the surface area of the reservoir available for drug transport should reach a maximum at the same time the volume of buffer imbibed described by the triexponential fit reaches a maximum, i.e., at 8.8 days.

In vitro release of $\left[{ }^{14} \mathrm{C}\right] E H D P$

The percent of $\left[{ }^{14} \mathrm{C}\right]$ EHDP delivered in vitro can be noted in Fig. 3 and Table 2. As a result of the rapid and extensive influx of buffer into the reservoirs at early time points, the continual loss of drug to the bulk receptor phase, and dilution of remaining drug by imbibed buffer, the internal drug concentration decreased with time. Thus, first-order release behavior for $\left[{ }^{14} \mathrm{C}\right]$ EHDP was observed (Fig. 3) and a classical analysis for a cylindrical reservoir having an internal drug solution of nonconstant thermodynamic activity was employed through use of Eqn. 2 (Baker, 1987):

$M(t)=M_{\infty}\left[1-\exp ^{(-A D K / V V) t}\right]$

where $M(t)$ and $M_{\infty}$ denote the amount of $\left[{ }^{14} \mathrm{C}\right]$ EHDP released at time $t$ and initially contained in the reservoir, respectively, $t$ is time (s), $A$ is the surface area of the reservoir $\left(\mathrm{cm}^{2}\right), D$ is the diffusion coefficient of $\left[{ }^{14} \mathrm{C}\right] \mathrm{EHDP}\left(\mathrm{cm}^{2} / \mathrm{s}\right), K$ is the partition coefficient $\left(C_{\text {memb }} / C_{\text {bulk }}\right), l$ is the membrane thickness $(\mathrm{cm})$, and $V$ is the internal volume of the reservoir $\left(\mathrm{cm}^{3}\right)$. Eqn. 2 assumed that $A, D, K, V$, and $l$ are constant. However,

TABLE 2

Inhibition of bioprosthetic heart valve calcification in rats using reservoir-based administration of EHDP (2l-day implants)

\begin{tabular}{lccccc}
\hline Group & $N$ & $\begin{array}{l}\text { Tissue Ca } \\
(\mu \mathrm{g} / \mathrm{mg})\end{array}$ & $\begin{array}{l}\text { EHDP released } \\
\text { in vivo } \\
(\%)\end{array}$ & $\begin{array}{l}\text { EHDP released } \\
\text { in vitro } \\
(\%)\end{array}$ \\
\hline Unimplanted & 7 & $3.0 \pm 0.5$ & - & - & $\begin{array}{l}\text { Growth } \\
(\%)\end{array}$ \\
Control & 10 & $120 \pm 13$ & - & - & 100 \\
Empty reservoir & 7 & $107 \pm 14$ & - & - & 98.9 \\
Reservoir & 10 & $4.5 \pm 1.4$ & $15.7 \pm 3.2$ & $3.2 \pm 0.6$ & 98.3 \\
\hline
\end{tabular}

\footnotetext{
a Calculated from exponential fit of the in vitro release curve.
} 


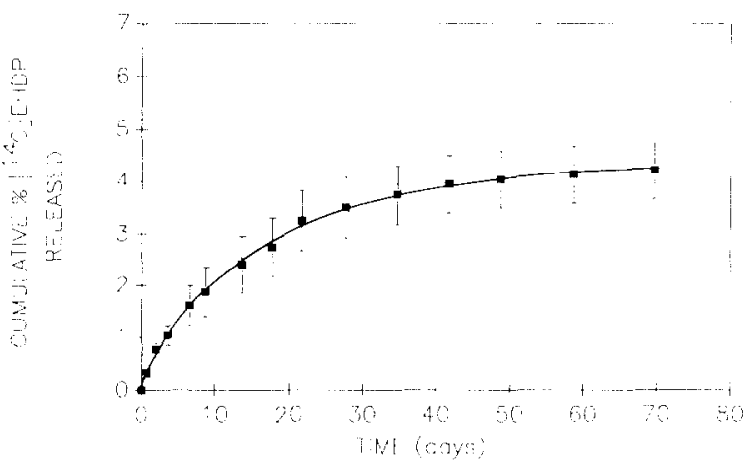

Fig. 3. Cumulative $\% \mathrm{Na}_{2}$ EHDP released in vitro from solvent-cast polyurethane reservoirs. (a) Mean $(n=5) \pm \mathrm{SE}$ : (-) nonlinear regression (Bolt et al.. 1984) fit of the data.

none of these variables are constant under the experimental conditions. Upon separation of the variables in Eyn. 2, followed by the natural logarithm and finally, the derivative of both sides of the expression, one obtains Eqn. 3:

$$
\frac{\mathrm{d} M(t)}{M_{\infty}-M(t)}-\frac{A(t) D(t) K(t)}{V(t) l(t)} \mathrm{d} t
$$

Recognizing, from geometrical considerations, that $A / V$ in Eqn. 3 is equal to $4 /$ dia $_{\text {res }}$ and defining $P(t)=D(t) K(t)$, the left-hand-side of Eqn. 3 can be set equal to $\left\{[4 P(\mathrm{t})] /\left[\mathrm{dia}_{\mathrm{res}}(t) l(t)\right]\right\} \mathrm{d} t$. Solving the resulting expression for $P(t)$ yields Eqn. 4 where $l(t)$ is assumed to be constant $(0.015 \mathrm{~cm})$ throughout the in vitro release period.

$$
P(t)=\frac{\mathrm{d}\left[\frac{M(t)}{M_{\varkappa}}\right]}{\mathrm{d} t} \cdot \frac{l \cdot \operatorname{dia}_{\mathrm{res}}(t)}{4\left(1-\left[\frac{M(t)}{M_{\infty}}\right]\right)}
$$

The slope $\mathrm{d}\left[M(t) / M_{x}\right] / \mathrm{d} t$ was determined from the release data shown in Fig. 3 at each time point. The time-dependent diameter of the reservoir was calculated from the dimensional changes based on the internal volume of the empty reservoir and the volume of buffer imbibed (Table 1) assuming the reservoir expanded in a uniform. cylindrical manner. Thus, the time-dependent permeability, $P(t)$, of the polyurethane test membrane to FHDP was calculated by using Eq. 4.
The calculated values of the mean permeability of the solvent-cast polyurethane reservoirs to EHDP using Eqn. 4 are shown in Fig. 4. The value of the permeability decreases throughout the 70 day in vitro release period and may be described by a biexponential equation with preexponential coefficients and characteristic time constants shown in Table 1.

Since the partition coefficient. $K=\left[{ }^{14} \mathrm{C}\right] \mathrm{EHD}-$ $\mathrm{P}_{\text {nemh }} /\left[{ }^{14} \mathrm{C}\right] \mathrm{EHDP} \mathrm{P}_{\text {hulk }}$, was independently determined by the solution depletion method (Zentner et al., 1978a) to have a value of $0.53 \pm$ 0.04 , the value of the diffusion coefficient, $D$, for $\left[{ }^{14} \mathrm{C}\right] \mathrm{EHDP}$ transport across MPU-5 was calculated $(D=D K / K$ ) as a function of time assuming that $K$ was constant throughout the 70 -day in vitro release period. However, it should be noted that the value of $D$ calculated as such is only an estimate of the true diffusivity due to a potentially time-dependent value of $K$. As expected with division by a constant, the value of $D$ plotted against time yields the same overall time-dependent profile as the value of $P$ with preexponential coefficients and characteristic time constants listed in Table 1.

Previous research (Lyman, 1964; Lyman and Kim, 1973a,b) has shown that solutes permeate polyether urethanes by a solution-diffusion or partition mechanism. This type of solute permeation is characterized by dissolution of the soiute in the membrane followed by diffusion along and between the polymer segments that make up the membrane structure (Zentner et al., 1978b). The

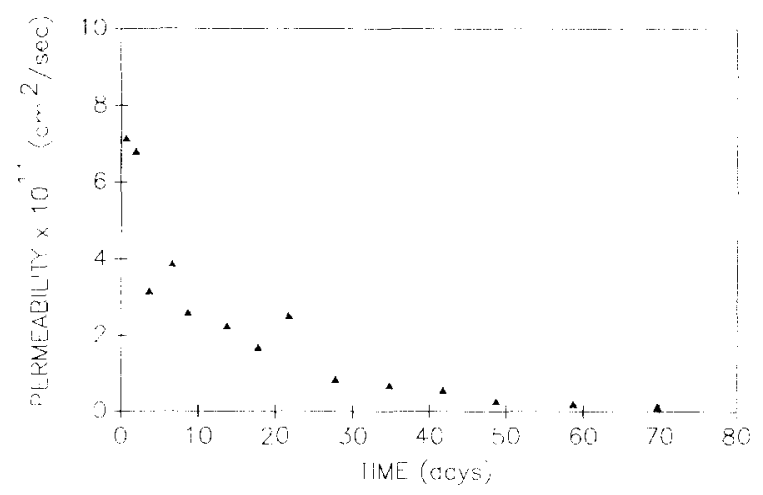

Fig. 4. Calculated values $(\Delta)$ of the mean $(n=5)$ permeability $(P=D K)$ of solvent-cast (Mitrathane reservoirs to $\mathrm{Na}_{2}$ EHDP. 
physical-chemical properties of the solute and the polyether urethane membrane play a major role in determining the membrane permeability with the solution-diffusion model (Zentner, 1978b). Interactions between the solute and the polymer segments of the membranes can greatly influence the value of the diffusion coefficient (Zentner, 1978b).

The time-dependent nature of $P$ in the present study would suggest that initially, buffer was imbibed with a concomitant rise in the osmotic-induced internal pressure. During the rapid reservoir swelling phase (first 7 days), the high osmotic-induced pressure inside the reservoirs appeared to cause a 'burst-effect' of EHDP through the reservoir membrane. Thereafter, the ionic strengths of both solutions (internal drug solution and external receptor phase) potentially approached an equilibrium value. This may account for the subsequent reduction in the mean value of the calculated permeability. EHDP may also form insoluble precipitates with components of the HEPES buffer or with polyurethane impurities. Assuming drug precipitation occurs in the lumen of the reservoir following approx. 7 days of in vitro release, the reservoir volume would then decrease to compensate for the loss of ions.

Changes in osmotic pressure and drug concentration in the lumen of the reservoir would appear to play an important role in affecting the value of $D$, and hence, $P$. Changes in the internal volume, osmotic pressure, drug concentration, and membrane thickness could all affect the value of $D$, since it is well documented that concentration, pressure, temperature, solvent properties, and the chemical nature of the diffusant may all affect the value of $D$ (Martin et al., 1983; Cussler, 1984; Flynn et al., 1974).

\section{In vivo efficacy of $E H D P$ delivered by reservoirs}

Reservoirs allowed to release $\left[{ }^{14} \mathrm{C}\right] \mathrm{EHDP}$ in vitro for 6 days prior to implantation into rats delivered $2.9 \pm 0.4 \%(3.3 \pm 0.5 \mathrm{mg})$ of EHDP. The EHDP released in vivo over 21 days was $15.7 \pm$ $3.2 \%$ (18.1 $\pm 3.7 \mathrm{mg})$. However, the greater release of EHDP in vivo $(15.7 \pm 3.2 \%)$ as compared to in vitro after 70 days $(4.2 \pm 0.6 \%)$ was possibly due to movement induced flexing and bending of the reservoir in the rat subdermal model coupled with possible hydrolytic degradation and subsequent microscopic cracking of the polyurethane membrane (Smith et al., 1987). Constant bending and flexing of the reservoirs in vivo may have caused slight leakage of the saturated $\mathrm{Na}_{2}$ EHDP solution from the sealed ends of the device.

EHDP administered by daily subcutaneous injections to rats is known to be associated with disturbed bone growth and altercd scrum calcium levels at doses exceeding $15 \mathrm{mg} / \mathrm{kg}$ per day (Levy et al., 1987). In the present study, complete inhibition of BHV-CALC (Table 2) was observed at an overall dosage of $3.0 \mathrm{mg} / \mathrm{kg}$ per day by local, reservoir-based administration of EHDP. Morphological examination revealed that pericardial tissue implanted without reservoirs and that implanted adjacent to empty reservoirs had diffuse minerali7ation with a morphology similar to that noted in previous studies (Golomb et al., 1986a; Johnston et al,, 1988). In contrast, tissue adjacent to EHDP-filled reservoirs had only minimal, focal calcific deposits, considerably diminished relative to control implants. Inhibition of BHV-CALC using this local controlled drug delivery approach was not associated with untoward effects on growth, bone development, or serum $\mathrm{Ca}^{2+}$ levels.

\section{Implications}

The present polyurethane drug delivery system has important implications for the prevention of bioprosthetic heart valve calcification. Reservoirs fabricated using ${ }^{\mathrm{R}}$ Mitrathane appeared to possess satisfactory mechanical strength despite stretching of the membrane in response to solvent influx. Both mechanical strength and biocompatibility would be a prerequisite for controlled drug delivery in the circulation where such a device would encounter different hydrodynamic conditions and pressure gradients.

By limiting the area available for solvent influx, the present reservoir system has the potential for zero-order release of EHDP. The polyurethane reservoirs might be engineered in such a way as to connect the lumen of the reservoir to a water-impermeable, biocompatible cannula that would lead to a percutaneous access device (PAD) situated subcutaneously. The reservoir could be refilled following drug exhaustion by a standand needle 
injection of a saturated solution of EHDP into a conveniently located PAD which had previously been implanted subcutaneously.

A refillable reservoir system might also enhance therapeutic efficacy when used in combination with EHDP containing matrices or osmotically driven pump systems. In addition, the possibility of further enhancing therapeutic benefit by combining EHDP drug delivery devices (refillable reservoirs, matrices, osmotic pumps, etc.) with BHV tissue pretreatment strategies also exists. The combination of treatment strategies would assure both short- and long-term release of EHDP to inhibit BHV CALC.

Refillable reservoir systems could be used for treating other cardiovascular diseases. A variely of cardiovascular drugs could be delivered at a constant rate by using this system. Those compounds less water-soluble than EHDP would be expected to permeate the reservoir membrane more slowly, result in less solvent/plasma uptake, and thereby. result in a more protracted zero-order release profile.

\section{Conclusions}

Based on the results of the present study. ${ }^{R}$ Mitrathane or other comparable medical-grade polyurethanes might be suitable rate-limiting membranes for use in a reservoir device containing Na-CaEHDP. Further sustaincd release of EHDP is possible by exploiting the low aqueous solubility of CaEHDP (Nash, 1984: Golomb et al.. 1987). Additional strategies to modify EHDP release rate would be varying either the total surface area available for solvent influx or the hydrophilicity (ratio of polyethylene glycol/urethane segments) of the copolymer.

Interaction of the EHDP anion with the polymer membrane used in the present study may contribute to a time-dependent diffusion coefficient for EHDP transport. Changes in the internal osmotic pressure, drug concentration, and membrane thickness as well as EHDP potentially forming insoluble precipitates with components of the Hepes buffer were additional variables suggested to contribute to the time-dependent value of the diffusion coefficient. Further studies are required to determine if alterations in the permeability of ${ }^{\mathrm{R}}$ Mitrathane to EHDP anion result from binding of the charged drug molecule to sites contained in the polyurethane and whether EHDP forms insoluble precipitates with components in Hepes buffer and/or impurities in the polyurethane membrane.

\section{Acknowledgments}

This work was supported, in part, by an American Heart Association, Michigan Affiliate award (T.P.J.) No. 343048 and an NHLBI grant (R.J.L.) No. RO1 HL38118 O2. R.J.L. is an Established Investigator of the American Heart Association No. 860166. The authors are grateful to Helen Shing and Sara Murray, Brigham and Women's Hospital, Boston, MA, for assisting in the preparation of the tissue specimens for morphologic analyses. Dr. Raymond P. D'Alonzo of Norwich Eaton Pharmaceuticals, Inc.. for providing sodium diphosphonate, and Dr. James J. Benedict formerly of Procter and Gamble, Inc.. for providing CaEHDP, $\mathrm{Na}_{2}\left[{ }^{14} \mathrm{C}\right] \mathrm{EHDP}$. and Mitrathane (MPU-5). The authors are also grateful to Mrs. Catherine Wongstrom for her excellent word processing assistance.

\section{References}

Arbustini. E, Jones, M., Moses, R.D.. Eidho, E..... Carroll R.J. and Ferrans. V.J.. Modification by the Hancock To process of calcification of bioprosthetic cardiac valves implanted in sheep. Am. I. Cardiol. $53(1984) 1388-1396$.

Baker, R.. Diffusion-comtrolled systems. In Baker, R. (Fd.)

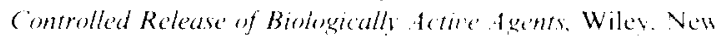
York. 1987, pp. 39-83.

Barnhart. G.R.. Jones, M., Ishihara, T., (haves, A.M. Rose. D.M. and Ferrans, V.l. Failure of porcine atortic and hovine pericardial prosthetic values: an experimental investigation in young sheep. (ireulutom, 66. (Suppl. 1) (1982a) $1-50$.

Barnhart. G.R. Jones. M.. Ishihara. T. Rose. D.M., (haves. A.M. and Ferrans. V.J., Degeneration and calcification of bioprosthetic cardiac valves: bioprosthetic tricuspid valve implantation in sheep. Am. I. Pathol. 106 (1982h) 136.139.

Bolt. Beranek and Newman Soltware Products (orporation.

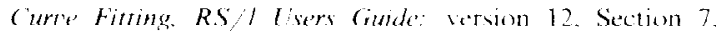


Book 2 (Graphic and Statistics), BBN Inc., Cambridge, MA, 1984, pp. 165-194.

Cussler, E.L.. Diffusion in concentrated solutions. In Cussler, E.L. (Ed.), Diffusion: Mass Transfer In Fluid Systems, Cambridge University Press, New York, 1984, pp. 55-84.

Fishbein, M.C., Levy, R.J., Ferrans, V.J., Dearden, L.C., Nashef, A., Goodman, A.P. and Carpentier, A., Calcification of cardiac valve prostheses: biochemical, histologic. and ultrastructural observations in a subcutaneous implantation model system. J. Thorac. Cardiovasc. Surg., 83 (1982) 602-609.

Flynn, G.L., Yalkowsky, S.H. and Roseman, T.J., Mass transport phenomena and models; theoretical concepts. $J$. Pharm. Sci., 63 (1974) 479-510.

Gallo, I., Nistal, F., Artinano, E., Fernandez, D., Cayon, R., Carrion, M. and Garcia-Martinez., V., The hehavior of pericardial versus porcine valve xenografts in the growing sheep model. J. Thorac. Cardiovasc. Surg. 93 (1987) 281-290.

Golomb, G., Langer, R., Schoen, F.J., Smith, M.S., Choi, Y.M. and Levy, R.J., Controlled release of diphosphonate to inhibit bioprosthetic heart valve calcification: dose-response and mechanistic studies. $J$. Controlled Release, 4 (1986a) 181-194.

Golomb, G., Dixon, M., Smith, M.S., Schoen, F.J. and Levy, R.J., Inhibition of bioprosthetic heart valve calcification by sustained local delivery of $\mathrm{Ca}^{2+}$ and $\mathrm{Na}^{+}$diphosphonate via controlled release matrices. Trans. Am. Soc. Artif. Intern. Organs, 32 (1986b) 587-590.

Golomb, G., Dixon, M., Smith, M.S., Schoen, F.J. and Levy, R.J., Controlled-release drug delivery of diphosphonates to inhibit bioprosthetic heart valve calcification; release rate modulation with silicone matrices via drug solubility and membrane coating. J. Pharm. Sci, 76 (1987) 271-276.

Hagler, H.K., Lopez, L.E., Murphy, M.E., Greico, C.A. and Buja, L.M., Quantitative X-ray microanalysis of mitochondrial calcification in damaged myocardium. Lab. Invest., 45 (1981) 241-247.

Johnston, T.P., Schoen, F.J. and Levy, R.J., Prevention of calcification of bioprosthetic heart valve leaflets by calcium diphosphonate pretreatment. J. Pharm. Sci., 77 (1988) $740-744$.

Karnovsky, M.J., A formaldehyde-glutaraldehyde fixative of high osmolality for use in electron microscopy. J. Cell. Biol, 27 (1965) 137A.

Levy, R.J., Zenker, J.A. and Lian, J.B., Vitamin K-dependent calcium binding proteins in aortic valve calcification. $J$. Clin. Invest., 65 (1980) 563-566.

Levy, R.J., Gundberg, C. and Scheinman, R., The identification of the vitamin $\mathrm{K}$-dependent bone protein, osteocalcin as one of the $\gamma$-carboxyglutamic acid containing proteins present in calcified atherosclerotic plaque. Atherosclerosis, 46 (1983a) 49-56.

Levy, R.J., Zenker, J.A. and Barnhard, W.F., Porcine bioprosthelic valve calcification in bovine left ventricle aorta shunts: studies of the deposition of vitamin K-dependent proteins. Ann. Thorac. Surg., 36 (1983b) 187-192.
Levy, R.J., Schoen, F.J, and Howard, S.L., Mechanism of calcification of porcine bioprosthetic aortic valve cusps: role of T-jymphocytes. Am. J. Cardiol., 52 (1983c) 629-631.

Levy, R.J., Schoen, F.J.. Levy, J.T., Nelson, A.C.. Howard, S.L. and Oshry, L.J., Biologic determinants of dystrophic calcification and osteocalcin deposition in glutaraldehyde-preserved porcine aortic valve leaflets implanted subcutaneously in rats. Am. J. Pathol., 113 (1983d) 143-155.

Levy, R.J., Schoen, F.J., Howard, S.L., Levy, J.T., Oshry, M. and Hawley, M.. Calcification of cardiac valve bioprostheses: host and implant factors. In Rubin, R.P.. Weiss, G.B. and Putney. J.W. Jr (Eds), Calcium In Biological Systems. Plenum, New York, 1985a, pp. 661-668.

Levy, R.J., Hawley, M.A., Schoen, F.J., Lund, S.A. and Liu. P.Y., Inhibition by diphosphonate compounds of calcification of porcine bioprosthetic heart valve cusps implanted subcutaneously in rats. Circulation, 71 (1985b) 349-356.

Levy. R.J., Wolfrum, J., Schoen, F.J., Hawley, M.A., Lund. S.A. and Langer, R., Inhibition of calcification of biopressthetic heart valves by local controlled-release diphosphonate. Science, 228 (1985c) 190-192.

Levy, R.J., Schoen, F.J., Lund, S.A. and Smith. M.S., Prevention of leaflet calcification of bioprosthetic heart valves with diphosphonate injection therapy: experimental studies of optimal dosages and therapeutic durations. J. Thorac. Cardiovasc. Surg., 94 (1987) 551-557.

I.yman, DI. New synthetic membranes for the dialysis of blood. Trans. Am. Soc. Artif. Intern. Organs, 10 (1964) $17-20$.

Lyman. D.J. and Kim, S.W., Membranes in artifical kidney devices: Part, present, and future. Biomater. Med. Devices Artif. Organs, 1 (1973a) 431-451.

Lyman, D.J. and Kim, S.W., Aqueous diffusion through partition membranes. J. Polym. Sci. Symp., 41 (1973b) 139-144.

Martin, A., Swarbrick, J. and Cammarata, A., Diffusion and dissolution. In Martin, A. et al. (Eds), Physical Pharmacy; Physical Chemical Principles In the Pharmaceutical Sciences, I ea \& Fehiger, Philadelphia, PA, 1983, pp. 399-444.

Milano, A., Bortolotti, U.. Talenti, E., Valfre, C., Arbustini, E., Valente, M., Mazzucco, A., Gallucci, V. and Thiene, G., Calcific degeneration as the main cause of porcine bioprosthetic valve failure. Am. J. Cardiol. 53 (1984) 1066-1070.

Nash, H.A.. Controlled release systems for contraception. In Langer, R.S. and D.L. Wise (Eds), Medical Applications of Controlled Release, Vol. II, CRC Press, Boca Raton. FL, 1984, pp. 35-64.

Pierce, W.S., Donachy, J.H. and Rosenberg, G., Calcification inside artificial hearts: inhibition by warfarin-sodium. Science. 208 (1980) 601-603.

Schoen, F.J. and Levy, R.J., Bioprosthetic heart valve failure: pathology and pathogenesis. Cardiol. Clin., 2 (1984) 717739 .

Schoen, F.J. and Hobson. C.E., Anatomic analysis of removed. prosthetic heart valves: causes of failure of 33 mechanical valves and 58 bioprostheses, 1980-1983. Hum. Pathol., 16 (1985) 549-559.

Schoen, F.J., Levy, R.J., Nelson, A.C., Bernhard, W.F., Nashef, 
A. and Hawley, M., Onset and progression of experimental bioprosthetic heart valve calcification. Lab. Invest., 52 (1985a) 523-532.

Schoen, F.J., Tsao, J.W. and Levy, R.J., Calcification of porcine aortic valves and bovine pericardium are equivalent. Trans Soc. Biomater, 8 (1985b) 13-16.

Schoen, F.J., Cardiac valve prostheses: pathological and bioengineering considerations. J. Cardiovasc. Surg., 2 (1987) 65-108.

Schoen, F.J., Harasaki, H., Kim, K.M., Anderson. H.C. and Levy, R.J., Biomaterial-associated calcification: pathology, mechanisms and strategies for prevention. J. Biomed. Mater. Res., 22 [A1 Suppl.] (1988) 11-36.

Smith, R., Williams, D.F. and Oliver, C., The biodegradation of poly(ether urethanes). J. Biomed. Mater. Res., 21 (1987) $1149-1166$.

Thubrikar, M.J., Deck, J.D., Aouad, J. and Nolan, S.P.. Role of mechanical stress in calcification of aortic bioprosthetic valves. I. Thorac Cardionasc. Surg. 86 (1983) 115-125.

Zentner, G.M., Cardinal, J.R. and Kim, S.W., Progestin permeation through polymer membranes $\mathrm{I}$; diffusion studies on plasma-soaked membranes. J. Pharm. Sci., 67 (1978a) 1347-1351.

Zentner, G.M., Cardinal, J.R. and Kim, S.W., Progestin permeation through polymer membranes 11: diffusion studies on hydrogel membranes. J. Pharm. Sci., 67 (1978b) 1352-1355. 